Miao Wang, Yadong Zhao and Jiebing Li*

\title{
Demethylation and other modifications of industrial softwood kraft lignin by laccase-mediators
}

https://doi.org/10.1515/hf-2017-0096

Received June 8, 2017; accepted December 4, 2017; previously published online March 9, 2018

Abstract: Substitution of phenol in phenol-formaldehyde (PF) resin preparations by technical lignins is hindered by the inherently lower reactivity of lignin compared to phenol. Demethylation of an industrial softwood kraft lignin (SKL) to improve its reactivity is the focus of this paper. To this purpose, kraft lignin (KL) was treated with two commercial laccases, NS51002 (L1) and NS51003 (L2), for $24 \mathrm{~h}$ in combination with three mediators, 2,2'-azinobis-(3ethyl-benzothiazoline-6-sulfonic acid) diammonium salt (ABTS), 1-hydroxybenzotriazole (HBT) and 2,2,6,6-tetramethylpiperidin-1-oxyl (TEMPO). The characterizations of the reaction solution and the resultant KL showed that methanol was released as a result of the methoxy group splitting from the aromatic rings, while such demethylation was dependent on the laccase-mediator system (LMS). The catechol structures formed, which were further oxidized to a quinone structures prone to polymerization, led to molecular mass increment. Also this reaction was LMS dependent. The same is true to the cleavage of $\beta-0-4^{\prime}$ linkages, which resulted in depolymerization. The L1-ABTS, L1-TEMPO and L2-HBT combinations are the most efficient and the resulting modified lignin would be suitable to phenol substitution. Challenging is the lignin polymerization following the demethylation, especially in case of L1-ABTS, which might inhibit the reactivity of the treated lignin.

Keywords: ${ }^{13} \mathrm{C}-\mathrm{NMR}, 2 \mathrm{D}-\mathrm{NMR},{ }^{31} \mathrm{P}-\mathrm{NMR}$, demethylation, FTIR, laccase, lignin, mediator, SEC

\footnotetext{
* Corresponding author: Jiebing Li, RISE Research Institutes of Sweden, SE-114 86, Stockholm, Sweden; and KTH Royal Institute of Technology, SE-100 44, Stockholm, Sweden, e-mail: jiebing.li@ri.se Miao Wang: RISE Research Institutes of Sweden, SE-114 86, Stockholm, Sweden; and KTH Royal Institute of Technology, SE-100 44, Stockholm, Sweden

Yadong Zhao: KTH Royal Institute of Technology, SE-100 44, Stockholm, Sweden
}

\section{Introduction}

Lignin is, after cellulose, the most abundant macromolecule in nature. Technical lignins are aromatic polymers containing phenolic $\mathrm{OH}$ groups, such as kraft lignin (KL) from the kraft pulping process, and are readily available (Rönnols et al. 2017). They are in principle suited for phenol substitution in phenol-formaldehyde (PF) resins, but their lower reactivity leads to deterioration of PF resin quality (Lewis and Lantzy 1989; Dunky and Pizzi 2002; Gandini and Belgacem 2008). A monomeric phenol has three reactive sites against formaldehyde in para and ortho positions to the $\mathrm{OH}$ group, while lignins are variously substituted in these positions. As known, lignin's aromatic nuclei may have p-hydroxyphenyl-(H), guaiacyl-(G) and syringyl-(S) structures, while the relative abundance of these units is plant species dependent (Liitiä et al. 2003; Boeriu et al. 2004). In all lignins, the para position is occupied by partially hydroxylated propyl chains. The ortho positions are either free (H-lignin) or mono-methoxylated (G-lignin) or dimethoxylated (S-lignin). Accordingly, the reactivity towards formaldehyde is in the order of $\mathrm{H}$-lignin $>\mathrm{G}$-lignin $>\mathrm{S}$-lignin. Demethylation has been reported as a way to activate different lignin structures (Hu et al. 2011), in the course of which methoxy groups are converted into phenolic groups, creating new para and ortho situated $\mathrm{OH}$ groups for the reaction with formaldehyde. For example, lignin-based PF resins prepared with demethylated wheat straw soda lignin is able to replace up to $60 \%$ of phenol, while the prepared resin still meets the requirements of Chinese national standard for premium type plywood manufacture (Wu and Zhan 2001). An et al. (1995) stated that demethylated KL is suited to a complete phenol substitution and the quality of prepared plywood is acceptable.

A thiol mediated demethylation reaction is found to be effective (Hu et al. 2014). The suitability of an odorless thiol-based reagent (Chae 2008) and iodocyclohexane (Zuo et al. 2008) were investigated for the demethylation of lignin monomers or dimers. The method was also applicable for KL demethylation (Birgersson 2015). On the other hand, more environmentally friendly biochemical methods were also tested successfully (Solomon and 
Lowery 1993; Ibrahim et al. 2011). Laccases (EC 1.10.3.2, $p$-diphenol:dioxygen oxidoreductase) are a group of multi-copper proteins found in many plants, fungi, and microorganisms (Solomon and Lowery 1993). Generally, the laccases need molecular oxygen to oxidize various aromatic and non-aromatic structures. They also play an important role in the biosynthesis of lignin by promoting the oxidative coupling of monolignols (Solomon and Lowery 1993; Solomon et al. 1996). The laccases differ mainly in their structures of the four copper centers, and have different redox potentials. In nature, "electron shuttles" are active between the substrate and laccase, which are called mediators and these combinations are commonly called "laccase-mediator system" (LMS). The mediator can even modulate the redox potential of the LMS system (Crestini and Argyropoulos 1998). LMSs play a versatile role in nature, whereas laccases alone are only able to oxidize phenolic compounds due to their comparatively low redox potentials (Bourbonnais and Paice 1990).

The LMS oxidations occur stepwise, where the initiation is followed by various subsequent reactions including demethylation (Lew 2014; Roth and Spiess 2015). The initiation mechanisms include phenolic hydrogen abstraction for phenolic lignin units and electron transfer (Bourbonnais et al. 1998), hydrogen atom transfer and ionic reaction steps (Fabbrini et al. 2002) for non-phenolic lignin units. The initial oxidative attack is primarily on the phenolic lignin moiety, followed by reactions on the nonphenolic structures (Martínez et al. 1994). Demethylation is limited to the laccases produced by fungi (Leonowicz et al. 1999). Other subsequent reactions include structural degradation (with release of phenolic residues) and oxidation of the side chain hydroxyl groups into aldehydes, ketones and acids (Bourbonnais and Paice 1990). The latter was useful to prepare benzaldehydes from benzyl alcohols (Rosenau et al. 1996) or aromatic methyl groups (Potthast et al. 1995). Additionally, polymerization may occur via the aromatic ring (Lundquist and Kristersson 1985) and ring opening reactions (Higuchi 1990). Compared to monomeric or dimeric models, few studies were dedicated to macromolecular lignins. Studies on lignin degradation by LMS have been reported for the delignification or bleaching of chemical pulps (Du et al. 2013b,c) and in biorefinery applications (Roth and Spiess 2015). Delignification mechanism with LMS was studied by Balakshin et al. (1999) after GPC and NMR analysis. The interaction of LMS and lignosulfonates, leading to polymerization, was also investigated (Areskogh et al. 2010). Demethylation of KL by LMS has also been studied, but the chemical analysis was generally restricted to the release of methanol (Ibrahim et al. 2011; Zou et al. 2015).
Clearly, a more comprehensive understanding of the LMS-lignin reactions is needed, which will be in focus of the present paper. Namely, the structural modification of softwood KL by two commercial laccases in combination with three mediators will be studied. The formation of methanol, and the modified lignin structures will be analyzed comprehensively.

\section{Materials and methods}

Materials: Softwood kraft lignin (SKL) was separated from industrial black liquor according to the LignoBoost process (Oehman et al. 2006). The SKL has a high purity: $98.45 \%$ lignin with low contents of ash (0.35\%) and carbohydrates (1.2\%) (Wang et al. 2017). The two laccases, N51002 (L1), prepared from a white-rot fungus (Trametes versicolor) and N51003 (L2), from Coprinopsis cinereus, were obtained from Novozyme (Denmark). All chemicals were purchased from Sigma-Aldrich: 2,2'-azinobis-(3-ethyl-benzothiazoline-6-sulfonic acid) diammonium salt (ABTS), 1-hydroxybenzotriazole hydrate (HBT), 2,2,6,6-tetramethylpiperidin-1-oxyl (TEMPO), polyoxyethylene sorbitanmonooleate (Tween 80), pre-wetted RC Tubing (Spectra/ Por $^{\circledR} 6$ Dialysis Membrane, MWCO 500 Da), 3,5-di-tert-butyl-1,2-benzoquinone (98\%) and 3-methylcatechol (99\%), as well as other chemicals and solvents in AR grades. The PTFE filters were from Millipore (Darmstadt, Germany).

Laccase-mediator treatment of SKL: Two grams (oven-dried weight) of SKL were suspended with one laccase and one mediator in $20 \mathrm{mM}$ $\mathrm{pH} 5$ sodium acetate buffer solution to produce a final volume of $200 \mathrm{ml}$, with concentrations of $10 \mathrm{mg} \mathrm{ml}^{-1} \mathrm{SKL}, 0.7 \mathrm{U} \mathrm{ml}^{-1}$ laccase and $1 \mathrm{mM}$ mediator. A small amount $\left(0.5 \mu \mathrm{l} \mathrm{ml}^{-1}\right)$ of Tween 80 was added to facilitate the suspensions of lignin and laccase. The mixture was incubated under stirring for $24 \mathrm{~h}$ at room temperature. After the reaction, a small amount $(0.1 \mathrm{ml})$ of the mixture was sampled for a $\mathrm{GC}$ analysis of the MeOH content and the rest was dialyzed (MWCO $500 \mathrm{Da}$ ) against running deionized water for $48 \mathrm{~h}$ and then lyophilized before further analysis. The recovery yield of modified lignin was around 95-98\%.

MeOH detection by GC analysis: The sampled solution was diluted 10 times with deionized water. $\mathrm{MeOH}$ was extracted with 1-butanol $(1: 1, \mathrm{v} / \mathrm{v})$. After standing for $10 \mathrm{~min}$, the top butanol phase was filtered via $0.2 \mu \mathrm{m}$ PTFE filters into a $2 \mathrm{ml} \mathrm{GC}$ vial. The GC instrument (Agilent $6890 \mathrm{GC}$, injector $250^{\circ} \mathrm{C}$ and detector $275^{\circ} \mathrm{C}$ ) was equipped with a FID detector for $\mathrm{MeOH}$ determination. A total of $1.5 \mu \mathrm{l}$ of sample was split injected (1/40), using the following: HP INNOWAX column (cross-linked polyethylene glycol, $15 \mathrm{~m} \times 0.25 \mathrm{~mm} \times 0.5 \mu \mathrm{m}$ ), He flow of $50 \mathrm{~cm} \mathrm{~s}^{-1}$, temperature program: $33^{\circ} \mathrm{C}$ for $0.5 \mathrm{~min} \rightarrow 233^{\circ} \mathrm{C}\left(50^{\circ} \mathrm{C}\right.$ $\mathrm{min}^{-1}$ ), holding time $1 \mathrm{~min}$. Dimethyl sulfoxide (DMSO) was served as an internal standard (IS).

Nuclear magnetic resonance (NMR) spectroscopy: The samples dissolved in DMSO- $d_{6}$ were analyzed by quantitative ${ }^{13} \mathrm{C}$ and $2 \mathrm{D}$ ${ }^{1} \mathrm{H}-{ }^{13} \mathrm{C}$ heteronuclear single quantum coherence (2D HSQC) NMR spectroscopy on a Bruker Avance $400 \mathrm{MHz}$ instrument using the standard Bruker pulse programs (Zhang and Gellerstedt 2007). From the ${ }^{13} \mathrm{C}$-NMR spectra, the methoxy (OMe) content per aromatic 
ring was obtained from the integration ratio of the OMe signal at $55.6 \mathrm{ppm}$ and the aryl peaks at $105-160 \mathrm{ppm}$; the latter was set as 6 (one aromatic ring). ${ }^{31}$ P-NMR was performed after adaption and modification of the protocols described in the literature (Granata and Argyropoulos 1995; Pu et al. 2011) to quantify the different hydroxyl groups. In detail, a dried lignin or lignin product sample $(30 \mathrm{mg}$ ) was dissolved in a mixture composed of $100 \mu \mathrm{l}$ pyridine/N,N-dimethylformamide (1:1), $100 \mu \mathrm{l}$ N-hydroxy-5-norbornene-2,3-dicarboxylic acid imide pyridine solution $\left(20 \mathrm{mg} \mathrm{ml}^{-1}\right)$ as IS and $100 \mu \mathrm{l}$ chromium acetylacetonate pyridine solution ( $5 \mathrm{mg}$ $\mathrm{ml}^{-1}$ ) as a relaxation agent. The reagent 2-chloro-4,4,5,5-tetramethyl-1,3,2-dioxaphospholane $(100 \mu \mathrm{l})$ was then added together with $400 \mu \mathrm{l}$ chloroform- $d$, and the mixture was stirred for $10 \mathrm{~min}$ for completion of the phosphitylation reaction before NMR analysis. For processing, the sharp signal of the IS at $151.9 \mathrm{ppm}$ was used, and the content of hydroxyl groups was obtained by integration of the following shift ranges: aliphatic $\mathrm{OH}$ (151.0-145.0 ppm), condensed phenolic $\mathrm{OH}$ including syringyl $\mathrm{OH}$ (145.0-140.4 ppm), guaiacyl phenolic $\mathrm{OH}$ (140.4-138.6 ppm), $p$-hydroxyphenyl phenolic OH (138.6-136.5 ppm) and carboxylic OH (136.5-133.2 ppm). MestReNova (Mnova) 7.1.2 software (Mestrelab Research S.L., Santiago de Compostela, Spain) was applied for data processing.

Fourier transform infrared (FTIR) spectroscopy: A Perkin-Elmer Spectrum 2000 FTIR spectrometer (Waltham, MA, USA) was applied, equipped with an attenuated total reflectance (ATR) system and a Specac MKII Golden Gate (Creekstone Ridge, GA, USA); with $4 \mathrm{~cm}^{-1}$ resolution, 16 scans were accumulated at room temperature. A blank scan was performed for background correction. The data processing was conducted by the Spectrum $10^{\mathrm{TM}}$ software as integral part of the equipment.

SEC analysis: The molecular mass distribution (MMD) was determined by means of three columns, Styragel HR1, Styragel HR2 and Styragel HR4, connected in series. Two hundred and fifty microliters of tetrahydrofuran (THF) with the dissolved sample was injected;
THF served as the mobile phase $\left(0.8 \mathrm{ml} \mathrm{min}^{-1}\right)$ by $\mathrm{UV}_{280 \mathrm{~nm}}$ detection (AZURA UVD 2.1S, Knauer, Berlin, Germany). The SEC system was calibrated with polystyrene standards with molecular masses from 162 to 3000000 Da by refractive index (RI) detection (Waters 2414) using third-degree polynomial fitting. Peak molecular mass $\left(M_{p}\right)$, weight average molecular mass $\left(M_{w}\right)$, number average molecular mass $\left(M_{n}\right)$ and polydispersity $(\mathrm{PD})$ indices $\left(\mathrm{M}_{\mathrm{w}} / \mathrm{M}_{\mathrm{n}}\right)$ were calculated by the Cirrus GPC software version 3.1 from Polymer Laboratories (Agilent).

\section{Results and discussion}

\section{Demethylation}

As revealed by ${ }^{31} \mathrm{P}-\mathrm{NMR}$ analysis (Figure 1), SKL shows features of a typical SKL, containing a noticeable amount of different phenolic rings with a total amount $\mathrm{OH}_{\text {phen }}$ of $4.57 \mathrm{mmol} \mathrm{g}^{-1}$ (Table 1). However, 44\% (2.01 $\mathrm{mmol} \mathrm{g}^{-1}$ ) of these are condensed with both ortho positions occupied and thus without reactive positions. The rest were mainly $\mathrm{G}$ units $\left(2.32 \mathrm{mmol} \mathrm{g}^{-1}\right)$, with one free ortho position on each unit, although some $\mathrm{H}$-units were present $\left(0.24 \mathrm{mmol} \mathrm{g}^{-1}\right)$ with two free ortho positions.

SKL was treated with the commercial laccases N51002 (L1) and N51003 (L2) in combination with the mediators, ABTS, HBT and TEMPO (Figure 2). After incubation, detectable amount of $\mathrm{MeOH}$ was released in all the six reaction solutions. However, the $\mathrm{MeOH}$ concentration was too low to be satisfactorily quantified. The more sensitive headspace analysis combined by ion flow tube-mass spectrometry (SIFT-MS) was applied for quantification

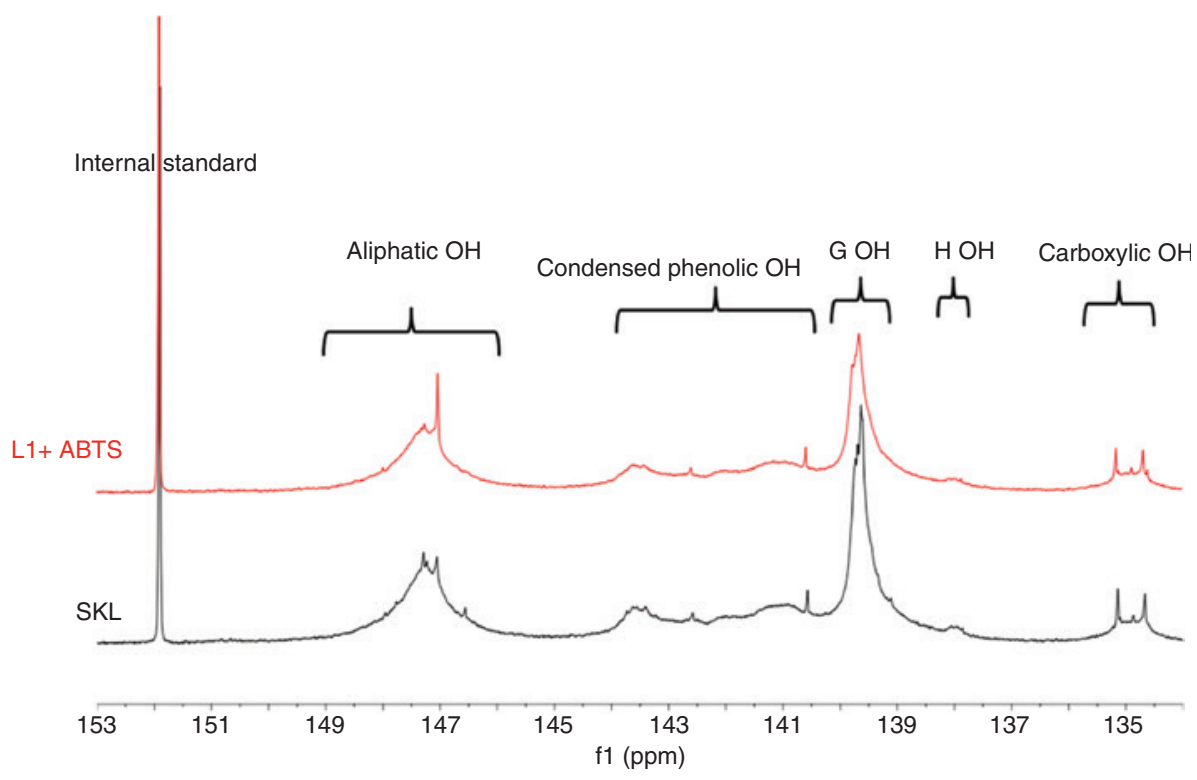

Figure 1: ${ }^{31} \mathrm{P}-\mathrm{NMR}$ spectra of softwood kraft lignin (SKL) before and after treatment by the laccase-mediator L1+ABTS. 
Table 1: Contents of methoxyl (OMe) groups per aromatic ring (by $\left.{ }^{13} \mathrm{C}-\mathrm{NMR}\right)$ and aliphatic, carboxylic $\mathrm{OH}$ groups and phenolic $\mathrm{OH}$ groups, such as $p$-hydroxyphenyl (H), guaiacyl (G) and condensed (cond.) units (by ${ }^{31} \mathrm{P}-\mathrm{NMR}$ ) of softwood kraft lignin (SKL) before and after laccasemediator treatment.

\begin{tabular}{|c|c|c|c|c|c|c|c|}
\hline \multirow[b]{2}{*}{ Sample } & \multirow[b]{2}{*}{${ }^{0 M e}$ per $\mathrm{C}_{6}$} & \multirow[b]{2}{*}{$\mathrm{OH}_{\mathrm{aliph}}\left(\mathrm{mmol} \mathrm{g}^{-1}\right)$} & \multicolumn{4}{|c|}{$\mathrm{OH}_{\text {phen }}\left(\mathrm{mmol} \mathrm{g}^{-1}\right)$} & \multirow{2}{*}{$\begin{array}{l}\text { Carboxylic. } \mathrm{OH} \\
\left(\mathrm{mmol} \mathrm{g}^{-1}\right)\end{array}$} \\
\hline & & & $\mathrm{G}-\mathrm{OH}$ & $\mathrm{H}-\mathrm{OH}$ & Cond. & Sum & \\
\hline$S K L^{a}$ & 0.94 & $1.91 \pm 0.16$ & $2.32 \pm 0.04$ & $0.24 \pm 0.07$ & $2.01 \pm 0.06$ & 4.57 & $0.46 \pm 0.01$ \\
\hline \multicolumn{8}{|l|}{ L1 } \\
\hline+ ABTS & 0.55 & $n d^{b}$ & $\mathrm{nd}^{\mathrm{b}}$ & $n d^{b}$ & $n d^{b}$ & $\mathrm{nd}^{\mathrm{b}}$ & $n d^{b}$ \\
\hline$+\mathrm{HBT}$ & 0.79 & 1.96 & 1.96 & 0.27 & 1.85 & 4.08 & 0.45 \\
\hline + TEMPO & 0.55 & 1.92 & 1.86 & 0.24 & 1.71 & 3.81 & 0.40 \\
\hline \multicolumn{8}{|l|}{$\mathrm{L} 2$} \\
\hline+ ABTS & 0.68 & 2.16 & 2.22 & 0.27 & 2.11 & 4.60 & 0.47 \\
\hline$+\mathrm{HBT}$ & 0.56 & 1.92 & 2.09 & 0.26 & 1.94 & 4.29 & 0.40 \\
\hline + TEMPO & 0.86 & 2.02 & 2.01 & 0.26 & 1.94 & 4.21 & 0.44 \\
\hline
\end{tabular}

Laccases, L1 = NS51002 and L2 = NS51003 and mediators; ABTS, 2,2'-azino-bis-(3-ethyl-benzothiazoline)-6-sulfonate; HBT, 1-hydroxybenzotriazole; TEMPO, 2,2,6,6-tetramethylpiperidin-1-oxyl.

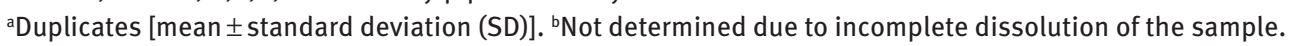

ABTS<smiles>CCn1/c(=N/N=c2/sc3cc(S(=O)(=O)O)ccc3n2CC)sc2cc(S(=O)(=O)O)ccc21</smiles><smiles>C=CC=[GeH2]</smiles><smiles>CCn1/c(=N/N=c2\sc3cc(S(=O)(=O)O)ccc3n2CC)sc2cc(S(=O)(=O)O)ccc21</smiles><smiles>C=C1C=C(C(=O)O)C1=C</smiles><smiles>CCn1/c(=N/N=c2/sc3cc(S(=O)(=O)O)ccc3n2CC)sc2cc(S(=O)(=O)O)ccc21</smiles>

HBT<smiles>On1nnc2ccccc21</smiles>

TEMPO

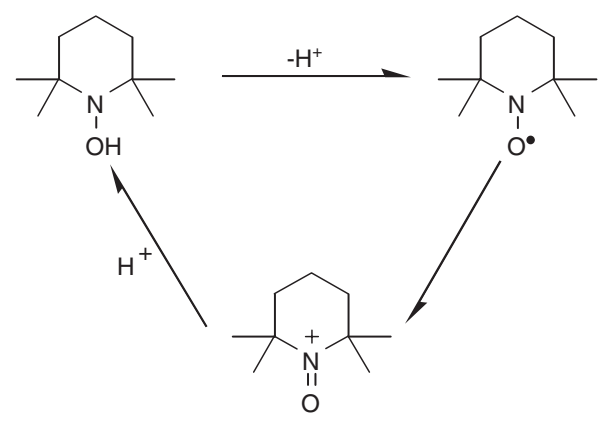

Figure 2: The redox reactions of mediators used in the study.

ABTS, 2,2'-Azinobis-(3-ethyl-benzthiazoline)-6-sulfonate; HBT, 1-hydroxybenzotriazole; TEMPO, 2,2,6,6-tetramethylpiperidin-1-oxyl.

in the literature (Zou et al. 2015). The OMe decrement in lignin was further confirmed in this present study by quantitative ${ }^{13} \mathrm{C}-\mathrm{NMR}$ (Figure 3). Three combinations, L1-ABTS, L1-TEMPO and L2-HBT, resulted in the highest $\mathrm{OMe}$ content reduction, resulting in "OMe/arom. ring" ratios of $0.55-0.56$, while the original ratio was 0.94 (Table 1). In the literature, a similar SKL demethylation rate of $40 \%$ was reported (Zou et al. 2015).
However, catechol structures were not observed in the LMS-treated SKL by ${ }^{31} \mathrm{P}-\mathrm{NMR}$ as no new signal appeared (Figure 1). In a control experiment with 3-methylcatechol, the corresponding catechol signals were detected at 142.23 and $142.17 \mathrm{ppm}$. This is because the LMS provides an oxidative environment and catechols are strong reductants. In one report, hydroquinone could easily be oxidized into quinone by laccase at room temperature (Cannatelli and 


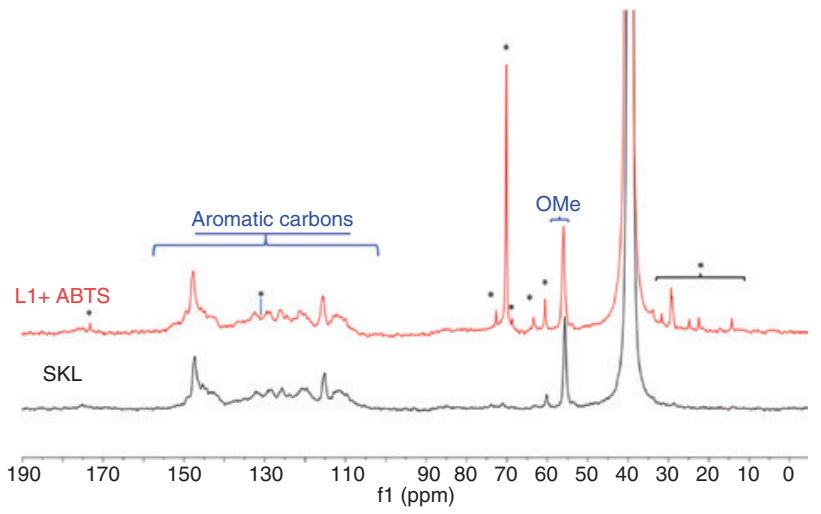

Figure 3: ${ }^{13} \mathrm{C}-\mathrm{NMR}$ spectra of softwood kraft lignin (SKL) before and after laccase-mediator treatment (representing by L1+ABTS). * Marked peaks are from contaminated Tween 80 according to (Zhang et al. 2015).

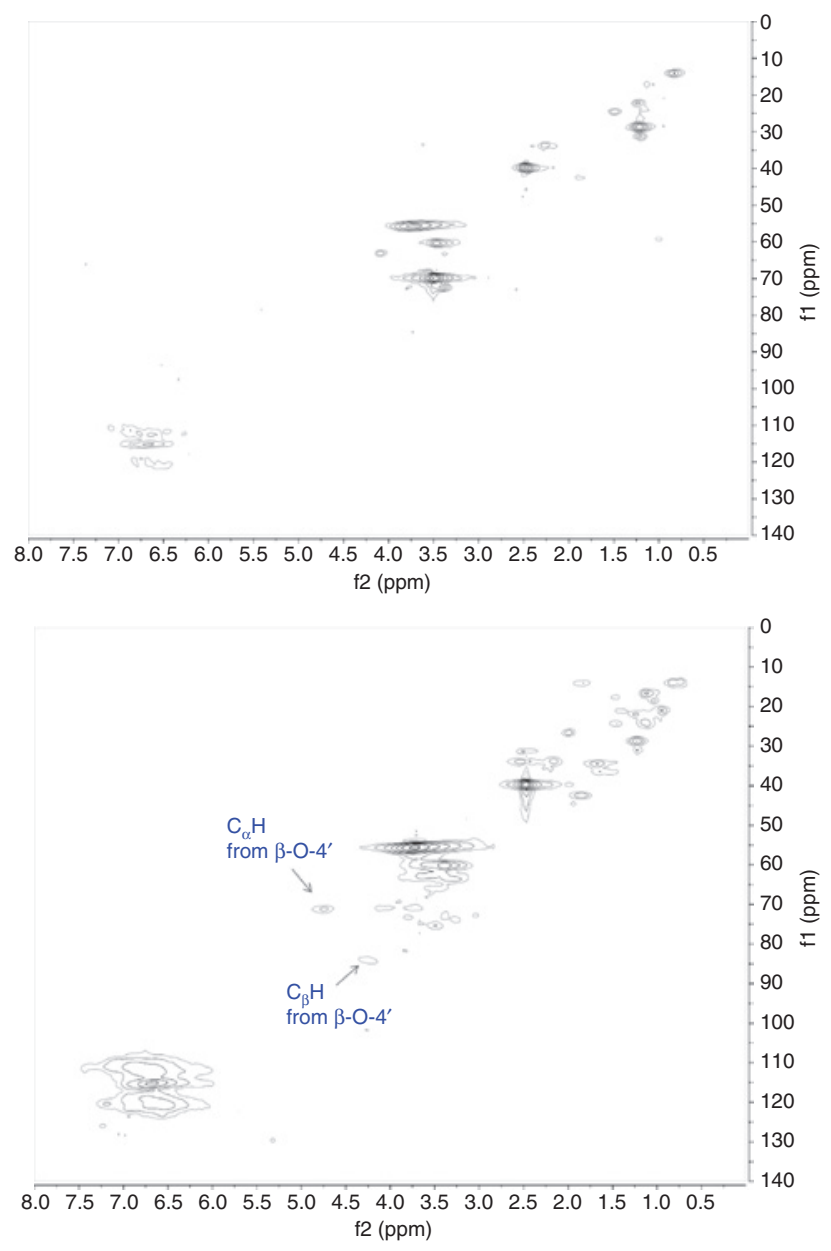

Figure 4: Two-dimensional (2D)-NMR spectra of softwood kraft lignin (SKL) before (bottom) and after laccase-mediator treatment (top) (representing by L1+ABTS).

Ragauskas 2015). However, no quinone structure in the modified lignin was seen by ${ }^{13} \mathrm{C}$-NMR. The ${ }^{13} \mathrm{C}-\mathrm{NMR}$ spectrum of the commercial 3,5-di-tert-butyl-1,2-benzoquinone showed two carbonyls at 180.45 and 179.70 ppm, which were absent in any of the laccase treated SKL samples (Figure 3). The sole carbonyl group signal observed at $172.88 \mathrm{ppm}$ was originated from the residual Tween 80 used in the incubation (Zhang et al. 2015). The charged amount of Tween 80 was low, while its signals at ${ }^{13} \mathrm{C}$-NMR were sharp and observable due to its shorter relaxing time than that of the polymeric lignin. Obviously these signals did not interfere with the lignin signals (Figure 3). Apparently, any formed quinones must have been reacted further for example via polymerization. A noticeable increase in the molecular mass of SKL was observed (see below), which is a sign for the polymerization. Note that the long laccase reaction time $(24 \mathrm{~h})$ used would give the opportunity for the polymerization. Quinone polymerization was in fact reported in the literature (Lundquist and Kristersson 1985).

\section{Other structural modifications}

The LMS treatment decreased the total amount of all $\mathrm{OH}_{\text {phen }}$ groups, from $4.57 \mathrm{mmol} \mathrm{g}^{-1}$ to $3.81-4.29 \mathrm{mmol} \mathrm{g}^{-1}$ (6-16\% decrement), except for the sample treated with L2-ABTS, which was apparently unaffected (Table 1). Cleavage of the $\beta-0-4^{\prime}$ linkages (see below) could also increase the phenolic content. The $\mathrm{OH}$ content of the sample treated with L1-ABTS could not be characterized due to incomplete solubilization, possibly because of its substantial polymerization (see below). $\mathrm{OH}_{\text {phen }}$ were the preferential targets of the LMS. G units were the most attacked structures, with the extent depending on the LMS combination applied (Table 1). A slight decrease (for L1 laccase) or no decrease (for L2 laccase) of $\mathrm{OH}_{\text {phen }}$ was observed in condensed units. The content of $\mathrm{H}$ units was unchanged after the LMS treatments. However, the quantification of the $\mathrm{H}$ units by ${ }^{31} \mathrm{P}-\mathrm{NMR}$ is not accurate because the peak intensity is very low and the spectra are noisy by the tail of the $G$ unit signals and there is a baseline shift (Figure 1). Camarero et al. (1994) reported on a significant $\mathrm{OH}_{\text {phen }}$ decrement during white rot fungi degradation.

In the 2D-NMR analysis, the typical lignin $\beta-0-4^{\prime}$ linkages are well visible based on the signals of $\mathrm{C}_{\alpha}-\mathrm{H}\left(\delta_{\mathrm{H}} / \delta_{\mathrm{C}}\right.$ : 4.74/71.3) and $\mathrm{C}_{\beta}-\mathrm{H}$ (4.24/84.2) (Du et al. 2013a). After the LMS treatment, the peak intensities were largely reduced in all of the modified lignins, and for the L1-ABTS treated sample the peaks completely vanished, indicating a comprehensive bond cleavage (Figure 4). This is in accordance with a lignin model study on L1-HBT, where $\beta-0-4^{\prime}$ cleavage was reported (Kawai et al.1999). Another example was 
described by Heap et al. (2014). The cleavage will lead to lignin depolymerization. It is also possible that side chain cleavage, including side chain oxidation, would also take place, leading to the disappearance of the $\beta-0-4^{\prime}$ signals.

Compared to the starting SKL, some fractions with shorter retention times (lignin fragments with higher molecular mass) were observed, especially for the L1-ABTS system (Figure 5). The peak molar mass $\left(M_{p}\right)$ increased from 2100 to 2300-3900, and reached an extremely high value of 10000 with L1-ABTS (Table 2). The $M_{w}$ generally increased three-fold, but reached a 30 -fold value of the original SKL in case of the L1-ABTS system (Table 2). A substantial PD increase was seen mainly in the L1-ABTS sample. The influence of the mediator coupling could be essential. Blank experiments were conducted either without laccases or without incubation that exclude the influence of possible contaminations from either the mediators or the laccases. The above mentioned quinone polymerization and cleavage of the $\beta$-aryl ether linkages may have been responsible for increases and decreases in

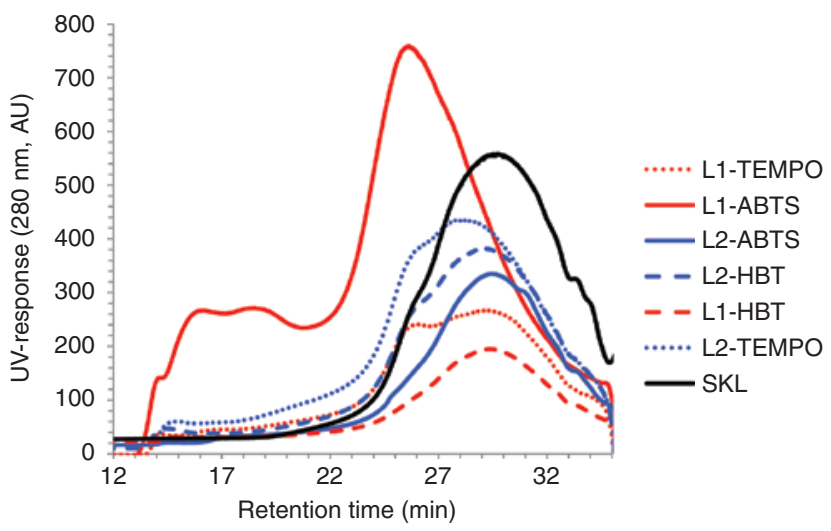

Figure 5: SEC profiles of softwood kraft lignin (SKL) before and after laccase-mediator treatments.

Table 2: The peak $\left(M_{p}\right)$, and number- $\left(M_{n}\right)$, and weight-average $\left(M_{w}\right)$ molecular mass and the polydispersity (PD) of softwood kraft lignin (SKL) before and after laccase-mediator treatment.

\begin{tabular}{lrrrr}
\hline Sample & $\mathbf{M}_{\mathrm{p}}$ & $\mathbf{M}_{\mathrm{n}}$ & $\mathbf{M}_{\mathrm{w}}$ & $\mathbf{P D}\left(\mathbf{M}_{\mathrm{w}} / \mathbf{M}_{\mathrm{n}}\right)$ \\
\hline SKL & 2100 & 1300 & 3800 & 2.9 \\
L1 & & & & \\
+ ABTS & 10000 & 4100 & 115000 & 28.1 \\
+ HBT & 2400 & 1700 & 10700 & 6.4 \\
+ TEMPO & 2400 & 1900 & 24700 & 13.1 \\
L2 & & & & \\
+ ABTS & 2300 & 1600 & 11000 & 6.9 \\
+ HBT & 2700 & 1800 & 15600 & 8.9 \\
+ TEMPO & 3900 & 2000 & 18400 & 9.3 \\
\hline
\end{tabular}

the molar mass (MM). Additionally, radical coupling reactions such as 5-5' coupling (Lundquist and Kristersson 1985) may have also contributed to the MM increment.

The FTIR spectra revealed changes between 700 and $800 \mathrm{~cm}^{-1}$ (Figure 6). Essentially, no changes occurred after the LMS treatments of SKL in case of L2, regardless of the mediator combinations, whereas absorption decrements around $775 \mathrm{~cm}^{-1}$ and increments around $725 \mathrm{~cm}^{-1}$ were observed in case of L1 treatment independently of the mediator. These bands are related to hydrogen deformation in substituted aromatic rings (Weigel and Herges 1992). Some alteration of the aromatic structures, for example, via condensation, might have occurred during the L1 treatments.

The initiation reactions by LMS also generate radicals in the side chain, such as benzyl radical. It has been demonstrated in lignin model studies that the benzyl radical is easily oxidized to $\mathrm{C}_{\alpha}$ carbonyl groups leading to benzyl aldehydes, ketones or acids (Camarero et al. 1994). Formation of an acid would be indicative for depolymerization. However, no additional carbonyl groups were observed by ${ }^{13} \mathrm{C}$-NMR - typical for ring opening reactions (Higuchi 1990) as manifested by signals at $51.6(\mathrm{MeO})$ and $166.9 \mathrm{ppm}$ (CO) (Evtuguin et al. 2009) were not seen either (Figure 3). Thus, the formation of muconic acid does not seem to be a major route in the modification of lignin by LMSs. Alternatively, any formed muconic acid would have reacted further during the targeted 24-h reaction time.

The amount of carboxylic hydroxyl groups, probably located on the side chains, was quantified by ${ }^{31} \mathrm{P}-\mathrm{NMR}$ (Table 1). In the literature, decarboxylation has been observed as another common type of laccase reaction

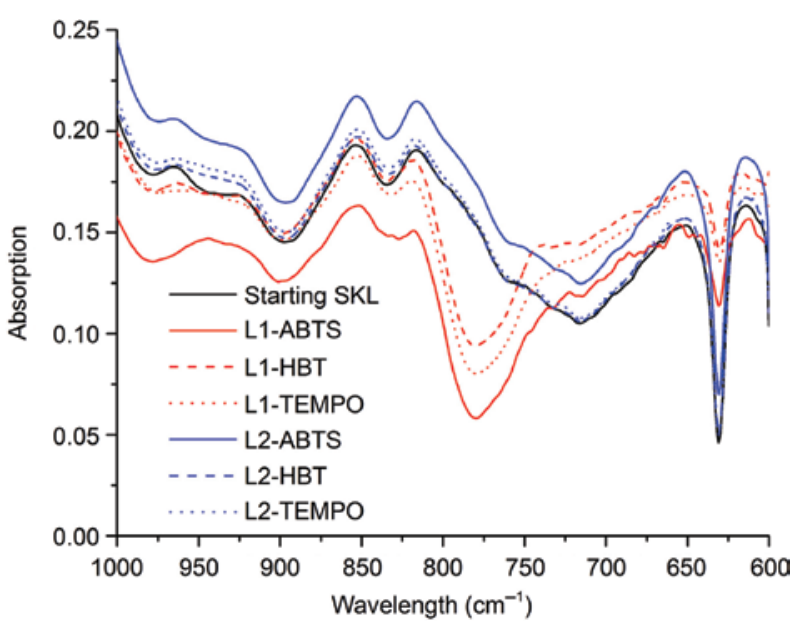

Figure 6: FTIR spectra of softwood kraft lignin (SKL) before and after laccase-mediator treatments. 
(Lundquist and Kristersson 1985). Although some $\mathrm{COOH}$ reductions were observed after LMS treatments, such a reaction was not observed as a general reaction in the present study.

\section{Influence of LMS combinations}

The two laccases originated from different fungi had slightly different redox potentials: $0.7 \mathrm{~V}$ for $\mathrm{L} 1$ and $0.5 \mathrm{~V}$ for L2 (Areskogh et al. 2010). The higher oxidation capacity of L1 may explain the generally higher decrement of $\mathrm{G}-\mathrm{OH}$ groups and of condensed $\mathrm{OH}_{\text {phen }}$ groups compared to laccase L2 (Table 1), as well as other differences, e.g. the aforementioned changes concerning the aromatic ring substitution patterns observed by FTIR.

Of the tested LMSs, ABTS in combination with L1 caused the most comprehensive modifications, i.e. the most comprehensive demethylation with $41 \%$ OMe decrement (Table 1) and the largest MM increment (Table 2 and Figure 5). In principle, laccases with low redox potentials (0.5-0.8 V), like the ones applied in this study, can only oxidize phenolic lignin units (Wong 2009), as oxidation of non-phenolic lignin requires a redox potential higher than $0.9 \mathrm{~V}$ (Schmidt 2007). However, the redox potential of L1 is high enough to oxidize the ABTS to both semi-oxidized $\mathrm{ABTS}^{+}$, with a redox potential of $0.68 \mathrm{~V}$, and fully oxidized $\mathrm{ABTS}^{2+}$, with a redox potential of 1.09 (Scott et al. 1993) (Figure 2). Therefore, after $\mathrm{ABTS}^{2+}$ formation, the L1-ABTS system was able to oxidize non-phenolic groups, which explains the most comprehensive effects observed. Bourbonnais and Paice (1990) observed the oxidation of non-phenolic model compounds with laccase/ABTS and Bourbonnais et al. (1997) described lignin demethylation by this system.

\section{Conclusion}

Demethylation occurred by laccase treatment as indicated by methanol formation and decrease of OMe content. However, the formed catechol intermediates could not be detected on the laccase-mediator modified lignin. Probably, catechols were further oxidized into reactive quinones, which are prone to polymerization leading to elevated MMs. The extent of lignin modification depends largely on the laccase-mediator combinations, among which the most effective was laccase L1 (NS51002) in combination with ABTS, which showed the highest redox potential and which was capable of oxidizing even nonphenolic lignin structures. There are two competing reactions: demethylation increases the lignin's reactivity, while the elevated MM has the opposite effect. Therefore, the combinations of L1-TEMPO and L2-HBT are preferred over L1-ABTS due to their similar ability to reduce OMe groups, but do not increase the MM too much. The applied 24-h reaction time might have been too long, and thus further work should be done at shorter reaction times.

Acknowledgment: The Chinese Scholarship Council (CSC) is acknowledged for supporting M. Wang for her $\mathrm{PhD}$ study. Associate Professor Elisabeth Sjöholm is thanked for instruction, guidance and improvement of the manuscript.

Author contributions: All the authors have accepted responsibility for the entire content of this submitted manuscript and approved submission.

Research funding: None declared.

Employment or leadership: None declared.

Honorarium: None declared.

\section{References}

An, X.N., Schroder, H.A., Thompson, G.E. (1995) Demethylated kraft lignin as a substitute for phenol. Chem. Ind. Forest Prod. 15:36-42.

Areskogh, D., Li, J., Henriksson, G. (2010) Investigation of the molecular weight increase of commercial lignosulfonates by laccase catalysis. Biomacromolecules 11:904-910.

Balakshin, M., Capanema, E., Chen, C.-L., Gratzl, J., Kirkman, A. (1999) Studies on the mechanism of pulp delignification with laccase-mediator system. Book of Abstracts, 217th ACS National Meeting, Anaheim, Calif., March 21-25 (1999), CELL-083.

Birgersson, E. (2015) Chemical methods to increase the reactivity of lignin: in the context of green chemistry and education for sustainable development. Master Thesis, Stockholm University.

Boeriu, C.G., Bravo, D., Gosselink, R.J.A., van Dam, J.E.G. (2004) Characterisation of structure-dependent functional properties of lignin with infrared spectroscopy. Ind. Crops Prod. 20:205-218.

Bourbonnais, R., Paice, M.G. (1990) Oxidation of non-phenolic substrates: an expanded role for laccase in lignin biodegradation. FEBS Lett. 267:99-102.

Bourbonnais, R., Paice, M.G., Freiermuth, B., Bodie, E., Borneman, S. (1997) Reactivities of various mediators and laccases with kraft pulp and lignin model compounds. Appl. Environ. Microbiol. 63:4627-4632.

Bourbonnais, R., Leech, D., Paice, M.G. (1998) Electrochemical analysis of the interactions of laccase mediators with lignin model compounds. Biochim. Biophys. Acta 1379:381-390.

Camarero, S., Galletti, G.C., Martinez, A.T. (1994) Preferential degradation of phenolic lignin units by two white rot fungi. Appl. Environ. Microbiol. 60:4509-4516. 
Cannatelli, M.D., Ragauskas, A.J. (2015) Laccase-catalyzed synthesis of 2,3-ethylenedithio-1,4-quinones. J. Mol. Catal. B: Enzym. 119:85-89.

Chae, J. (2008) Practical demethylation of aryl methyl ethers using an odorless thiol reagent. Arch. Pharmacal Res. 31:305-309.

Crestini, C., Argyropoulos, D.S. (1998) The early oxidative biodegradation steps of residual kraft lignin models with laccase. Biorg. Med. Chem. 6:2161-2169.

Du, X., Gellerstedt, G., Li, J. (2013a) Universal fractionation of lignincarbohydrate complexes (LCCs) from lignocellulosic biomass: an example using spruce wood. Plant J. 74:328-338.

Du, X., Li, J., Gellerstedt, G., Rencoret, J., Del Rio, J.C., Martinez, A.T., Gutierrez, A. (2013b) Understanding pulp delignification by laccase-mediator systems through isolation and characterization of lignin-carbohydrate complexes. Biomacromolecules 14:3073-3080.

Du, X., Martin, M.E.E., Li, J. (2013c) Improvement of kraft pulp bleaching by treatments with laccase, urea, and refining. Holzforschung 67:651-658.

Dunky, M., Pizzi, A. (2002) Chapter 23 - Wood adhesives A2 - Dillard, D.A. In: Adhesion Science and Engineering. Eds. Pocius, A.V., Chaudhury, M. Elsevier Science B.V., Amsterdam. pp. 1039-1103.

Evtuguin, D.V., Rocha, G., Goodfellow, B.J. (2009) Detection of muconic acid type structures in oxidised lignins using 2D NMR spectroscopy. Holzforschung 63:675-680.

Fabbrini, M., Galli, C., Gentili, P. (2002) Comparing the catalytic efficiency of some mediators of laccase. J. Mol. Catal. B: Enzym. 16:231-240.

Gandini, A., Belgacem, M.N. (2008) Lignins as components of macromolecular materials. Elsevier Ltd., Amsterdam. pp. 243-271.

Granata, A., Argyropoulos, D.S. (1995) 2-Chloro-4,4,5,5-tetramethyl-1,3,2-dioxaphospholane, a reagent for the accurate determination of the uncondensed and condensed phenolic moieties in lignins. J. Agric. Food Chem. 43:1538-1544.

Heap, L., Green, A., Brown, D., Van Dongen, B., Turner, N. (2014) Role of laccase as an enzymatic pretreatment method to improve lignocellulosic saccharification. Catal. Sci. Technol. 4:2251-2259.

Higuchi, T. (1990) Lignin biochemistry: biosynthesis and biodegradation. Wood Sci. Technol. 24:23-63.

Hu, L., Hui, P., Yonghong, Z., Meng, Z. (2011) Methods to improve lignin's reactivity as a phenol substitute and as replacement for other phenolic compounds: a brief review. Bioresources 6:3515-3525.

Hu, L., Pan, H., Zhou, Y., Hse, C.-Y., Liu, C., Zhang, B., Xu, B. (2014) Chemical groups and structural characterization of lignin via thiol-mediated demethylation. J. Wood Chem. Technol. 34:122-134.

Ibrahim, V., Mendoza, L., Mamo, G., Hatti-Kaul, R. (2011) Blue laccase from Galerina sp.: properties and potential for Kraft lignin demethylation. Process Biochem. 46:379-384.

Kawai, S., Nakagawa, M., Ohashi, H. (1999) Aromatic ring cleavage of a non-phenolic beta-0-4 lignin model dimer by laccase of Trametes versicolor in the presence of 1-hydroxybenzotriazole. FEBS Lett. 446:355-358.

Leonowicz, A., Luterek, J., Wasilewska, M.W., Matuszewska, A., Hofrichter, M., Ziegenhagen, D., Rogalski, J., Cho, N.-S. (1999) The role of fungal laccase in biodegradation of lignin. Polpu, Chongi Gisul. 31:1-11.
Lew, P.C. (2014) Lignin biodegradation with laccase-mediator systems. Front. Energy Res. 2:1-13.

Lewis, N.G., Lantzy, T.R. (1989) Lignin in adhesives. Introduction and historical perspective. ACS Symp. Ser. 385:13-26.

Liitiä, T.M., Maunu, S.L., Hortling, B., Toikka, M., Kilpeläinen, I. (2003) Analysis of technical lignins by two- and three-dimensional NMR spectroscopy. J. Agric. Food. Chem. 51:2136-2143.

Lundquist, K., Kristersson, P. (1985) Exhaustive laccase-catalysed oxidation of a lignin model compound (vanillyl glycol) produces methanol and polymeric quinoid products. Biochem. J. 229:277-279.

Martínez, A.T., Camarero, S., Guillén, F., Gutiérrez, A., Muñoz, C., Varela, E., Martínez, M.J., Barrasa, J., Ruel, K., Pelayo, J. (1994) Progress in biopulping of non-woody materials: chemical, enzymatic and ultrastructural aspects of wheat straw delignification with ligninolytic fungi from the genus Pleurotus. FEMS Microbiol. Rev. 13:265-273.

Oehman, F., Theliander, H., Norgren, M., Tomani, P., Axegaard, P. (2006) Method for separating lignin from a lignin containing liquid/slurry, WO 2006038863.

Potthast, A., Rosenau, T., Chen, C.L., Gratzl, J.S. (1995) Selective enzymic oxidation of aromatic methyl groups to aldehydes. J. Org. Chem. 60:4320-4321.

$\mathrm{Pu}$, Y., Cao, S., Ragauskas, A.J. (2011) Application of quantitative ${ }^{31} \mathrm{P}$ NMR in biomass lignin and biofuel precursors characterization. Energy Environ. Sci. 4:3154-3166.

Rönnols, J., Jacobs, A., Aldaeus, F. (2017) Consecutive determination of softwood kraft lignin structure and molar mass from NMR measurements. Holzforschung 71:563-570.

Rosenau, T., Potthast, A., Chen, C.L., Gratzl, J.S. (1996) A mild, simple and general procedure for the oxidation of benzyl alcohols to benzaldehydes. Synth. Commun. 26:315-320.

Roth, S., Spiess, A.C. (2015) Laccases for biorefinery applications: a critical review on challenges and perspectives. Bioprocess Biosyst. Eng. 38:2285-2313.

Schmidt, O. (2007) Indoor wood-decay basidiomycetes: damage, causal fungi, physiology, identification and characterization, prevention and control. Mycol. Prog. 6:281-281.

Scott, S.L., Chen, W.J., Bakac, A., Espenson, J.H. (1993) Spectroscopic parameters, electrode potentials, acid ionization constants, and electron exchange rates of the 2,2[prime]azinobis(3-ethylbenzothiazoline-6-sulfonate) radicals and ions. J. Phys. Chem. 97:6710-6714.

Solomon, E.I., Lowery, M.D. (1993) Electronic structure contributions to function in bioinorganic chemistry. Science 259:1575-1581.

Solomon, E.I., Sundaram, U.M., Machonkin, T.E. (1996) Multicopper oxidases and oxygenases. Chem. Rev. 96:2563-2606.

Wang, M., Sjöholm, E., Li, J. (2017) Fast and reliable quantification of lignin reactivity via reaction with dimethylamine and formaldehyde (Mannich reaction). Holzforschung 71:27-34.

Weigel, U.M., Herges, R. (1992) Automatic interpretation of infrared spectra: recognition of aromatic substitution patterns using neural networks. J. Chem Inf. Model. 32:723-731.

Wong, D. (2009) Structure and action mechanism of ligninolytic enzymes. Appl. Biochem. Biotechnol. 157: 174-209.

Wu, S., Zhan, H.Y. (2001) Characteristics of demethylated wheat straw soda lignin and its utilization in lignin-based phenolic formaldehyde resins. Cellulose Chem. Technol. 35:253-262. 
Zhang, L., Gellerstedt, G. (2007) Quantitative 2D HSQC NMR determination of polymer structures by selecting suitable internal standard references. Magn. Reson. Chem. 45:37-45.

Zhang, Q., Wang, A., Meng, Y., Ning, T., Yang, H., Ding, L., Xiao, X., Li, X. (2015) NMR Method for accurate quantification of polysorbate 80 copolymer composition. Anal. Chem. 87:9810-9816.
Zou, L., Ross, B.M., Hutchison, L.J., Christopher, L.P., Dekker, R.F.H., Malek, L. (2015) Fungal demethylation of kraft lignin. Enzyme Microb. Technol. 73-74:44-50.

Zuo, L., Yao, S., Wang, W., Duan, W. (2008) An efficient method for demethylation of aryl methyl ethers. Tetrahedron Lett. 49:4054-4056. 